\title{
Preparation and catalytic performance of high dispersion of $Y$ zeolite treated with alkali solution
}

\author{
Zhaoyong Liu ${ }^{1,2} \cdot$ Zhongdong Zhang $^{1,2} \cdot$ Jianing Zhai ${ }^{2} \cdot$ Pusheng Liu ${ }^{2} \cdot$ \\ Chaohe Yang 1
}

Received: 16 June 2015/ Accepted: 6 August 2015/Published online: 15 August 2015

(c) The Author(s) 2015. This article is published with open access at Springerlink.com

\begin{abstract}
Y}$ zeolite slurry contains a lot of colloid and pretreatment of $\mathrm{Y}$ zeolite slurry could separate $\mathrm{Y}$ zeolite nanoparticles and $\mathrm{Si}$ sol effectively by alkali solution. These nanoparticles were characterized by scanning electron microcopy, particle size distribution, X-ray diffraction, thermogravimetric analysis, and $\mathrm{NH}_{3}$ temperature program desorption. After integrating the $\mathrm{Y}$ zeolite in fluid catalytic cracking catalyst, performance of the catalyst containing this nano-zeolite was evaluated by cracking the mixed feed of Xinjiang vacuum gas oil and vacuum resin in fixedfluidized-bed reactor. This catalyst is favorable for the production of light oil by catalytic cracking the mixed feed.
\end{abstract}

Keywords Y zeolite - High dispersion - Modified ·

Catalytic performance

\section{Introduction}

In recent years, the demand for catalyst with high activity and activity stability has been growing strongly in China. As domestic feedstock of chemical industry was becoming more and more inferior, $\mathrm{Y}$ zeolites, which were the major rate-controlling components in most modern hydrogen cracking catalysts, should remain extremely stable during cracking. Nowadays, almost all zeolitic fluid catalytic cracking (FCC) catalysts are prepared by the ion-exchange

Zhaoyong Liu

1zy0539@126.com

1 State Key Laboratory of Heavy Oil Processing, China University of Petroleum, 266555 Tsingdao, China

2 Lanzhou Chemical Engineering R\&D Center, PetroChina, 730060 Lanzhou, China of rare-earth (RE) cations owing to the high activity and proper hydrothermal stability in many reactions.

$\mathrm{Y}$ zeolite is widely used in petrochemical field as catalytic material and usually modification is needed to improve its hydrothermal stability and catalytic performance [1-3]. There is a high content of gel in $\mathrm{Y}$ zeolite crystallization seriflux that can not be efficiently removed by zeolite filtration and separation process and thus leaded to Y zeolite's low degree of crystallinity, undesirable dispersion and stability [4]. Therefore, before modifying $\mathrm{NaY}$ zeolite, it is critical to remove the gel that is attached to the surface of Y zeolite.

\section{Experimental}

\section{Experiment raw material}

The chemical materials used in this experiment are shown in Table 1.

\section{Preparation of high dispersion Y zeolite}

During the filtration and isolation of NaY crystalline system, the $\mathrm{NaY}$ zeolite was first washed with $0.1 \mathrm{M}$ alkaline solution 2-5 times at $80{ }^{\circ} \mathrm{C}$, and then 3-5 times of water of the weight of zeolite dry basis is used to wash the zeolite filter cake to thoroughly remove residue inorganic salt ions, especially silicate ions in order to prepare high performance NaY zeolite.

With conventional $\mathrm{NaY}$ and novel $\mathrm{NaY}$ zeolite as raw material, we prepared rare earth modified Y zeolite through traditional two times ion exchange and calcinations process. In the catalyst preparation process, one $\mathrm{Y}$ zeolite, a Kaolin matrix (Suzhou Kaolin Company, China), and 
Table 1 Sources and specifications of raw material

\begin{tabular}{llll}
\hline Raw material & Chemical formula & Sources & Specifications \\
\hline Y zeolite & $\mathrm{Na}_{56} \mathrm{Si}_{136} \mathrm{Al}_{56} \mathrm{O}_{384}$ & Catalyst plant of Lanzhou petrochemical company & Manufactured goods \\
Rare earth chloride solution & $\mathrm{RECl}_{3}$ & Catalyst plant of Lanzhou petrochemical company & Manufactured goods \\
Hydrochloric acid & $\mathrm{HCl}$ & Baiyin Liangyou chemical reagent company & Chemical pure \\
Sodium hydroxide & $\mathrm{NaOH}$ & Baiyin Liangyou chemical reagent company & Chemical pure \\
\hline
\end{tabular}

alumina sol matrix, were mixed together and shaped spraydrying to obtain a micropheroidal catalyst. Then we prepared CAT-1 sample containing conventional Y zeolite and CAT-2 sample containing novel Y zeolite through catalyst preparation process, respectively.

\section{Characterization}

The degree of crystallinity and unit cell size (UCS) were analyzed with a Rigaku D/MAX-3CX diffractometer. The pore properties of catalysts were tested in a Coulter Omnisorp 360 analyzer. The samples were first outgassed at $300{ }^{\circ} \mathrm{C}$ for $4 \mathrm{~h}$ with a vacuum degree of $1.33 \times 10^{-7} \mathrm{~Pa}$. The particle morphology and particle size of the samples were observed by SEM, which was carried out on S-4800 (Hitachi Company, acceleration voltage of $0.5-20 \mathrm{kV}$ ). FT-IR spectroscopy was performed on a Nexus FT-IR instrument (Nicolet Co, USA) to study the acidity of zeolite. Pretreatment of the sample was made in the cell at $300^{\circ} \mathrm{e}$ under vacuum for $2 \mathrm{~h}$. Then purified pyridine vapor was adsorped on the zeolite at room temperature. The excess of pyridine was removed under vacuum over two consecutive $(1 \mathrm{~h})$ periods of heating at 200 and $350{ }^{\circ} \mathrm{C}$, respectively, each of them followed by IR measurements. The particle size distribution of zeolites was observed by a laser particle size analyzer with measuring range from 0.05 to $500 \mu \mathrm{m}$.

\section{Catalyst evaluation}

\section{Evaluation device}

The fixed fluidization bed FCC unit (we call it FFB briefly) is used to evaluate catalysts' performances, which is designed by Luoyang Petrochemical Engineering Corporation Ltd, Sinopec [5].

\section{Evaluation method}

At the beginning of the experiment, a certain amount of fluidization wind is blown into the fixed fluidization bed FCC unit, and then the vacuum pump starts to load $200 \mathrm{~g}$ of catalyst into reactor. After loading the feedstock to gauge tank and heated to a certain temperature, the water pump starts to send distilled water into vaporizing oven to generate over heated steam. The steam is first used to replace fluidization wind and then used as atomization and strip steam. When each part of the reactor's temperatures is stabilized for $5 \mathrm{~min}$ and the feedstock has reached given temperature, the oil pump is started for reflux for 2 min to make sure the accuracy of input quantity of feedstock. The feedstock flows to the bottom of reactor along the central axis from top to bottom through feed pipes. The feedstock then contacts high temperature catalysts through nozzle and starts cracking reaction. After half an hour's steam stripping, oxygen is let into regenerate the spent catalyst. The condensing system will separate reaction product into liquid and gas.

The tests were carried out under the typical conditions for FCC units: cracking temperature $500{ }^{\circ} \mathrm{C}$, catalyst to oil mass ratio 4.0 , weight hourly space velocity $15 \mathrm{~h}^{-1}$. Prior to a FFB test, CAT- 1 and CAT-2 were steam-deactivated at $800{ }^{\circ} \mathrm{C}$ for $10 \mathrm{~h}$ in a fluid bed with $100 \%$ steam. The chemical composition of the product FCC gasoline was determined by an online GC-MS. The feedstock (as shown in Table 2) was a mixture of $70 \%$ Xinjiang vacuum gas oil (VGO) and $30 \%$ Xinjiang vacuum tower bottom (VTB).

\section{Results and discussion}

\section{Particle size and SEM analysis}

By improving zeolites' dispersion ability and reducing zeolites' particle size, zeolites' surface area can be

Table 2 Main properties of Xinjiang feedstock

\begin{tabular}{llll}
\hline Items & $\begin{array}{l}\text { Xinjiang } \\
\text { VTB }\end{array}$ & $\begin{array}{l}\text { Xinjiang } \\
\text { VGO }\end{array}$ & $\begin{array}{l}\text { Mixture } \\
(\mathrm{VTB} \\
\text { /VGO }=3 / 7)\end{array}$ \\
\hline Density $\left(20{ }^{\circ} \mathrm{C}\right)\left(\mathrm{g} \mathrm{cm}^{-3}\right)$ & 944.2 & 883.8 & 901.8 \\
Conradson carbon $(\mathrm{wt} . \%)$ & 9.87 & 0.07 & 3.10 \\
Average molecule $(\mathrm{g} / \mathrm{mol})$ & 828 & 319 & 390 \\
Simulated distillation $\left({ }^{\circ} \mathrm{C}\right)$ & & & \\
IBP & 420 & 286 & 306 \\
$10 \%$ & 435 & 347 & 339 \\
$30 \%$ & 465 & 392 & 372 \\
$50 \%$ & - & 392 & 372 \\
$70 \%$ & - & 453 & 416 \\
$90 \%$ & - & - & 502 \\
\hline
\end{tabular}




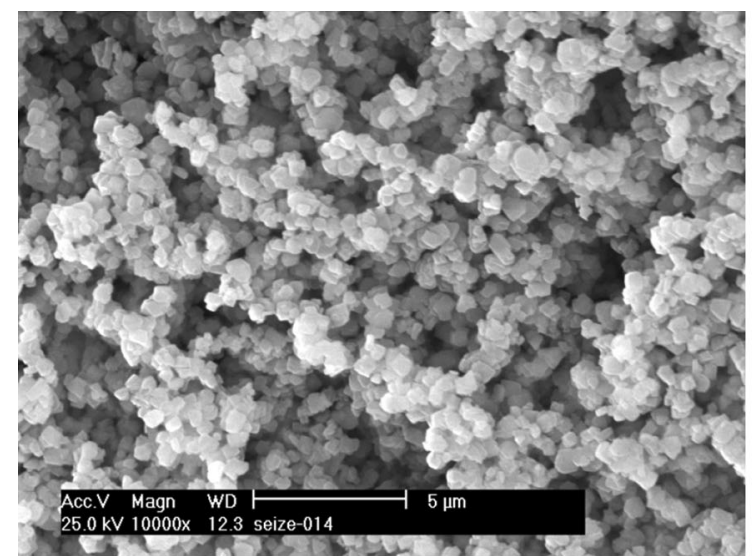

Conventional Y zeolite

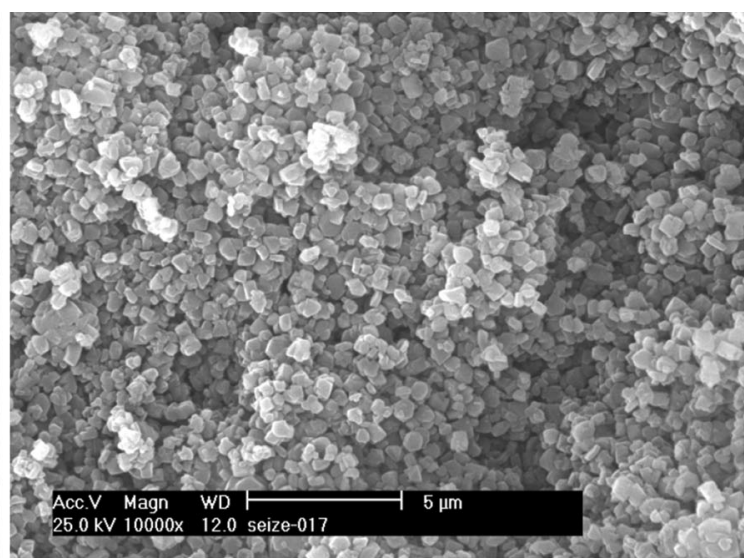

Novel Y zeolite

Fig. 1 SEM of the novel and conventional Y zeolite

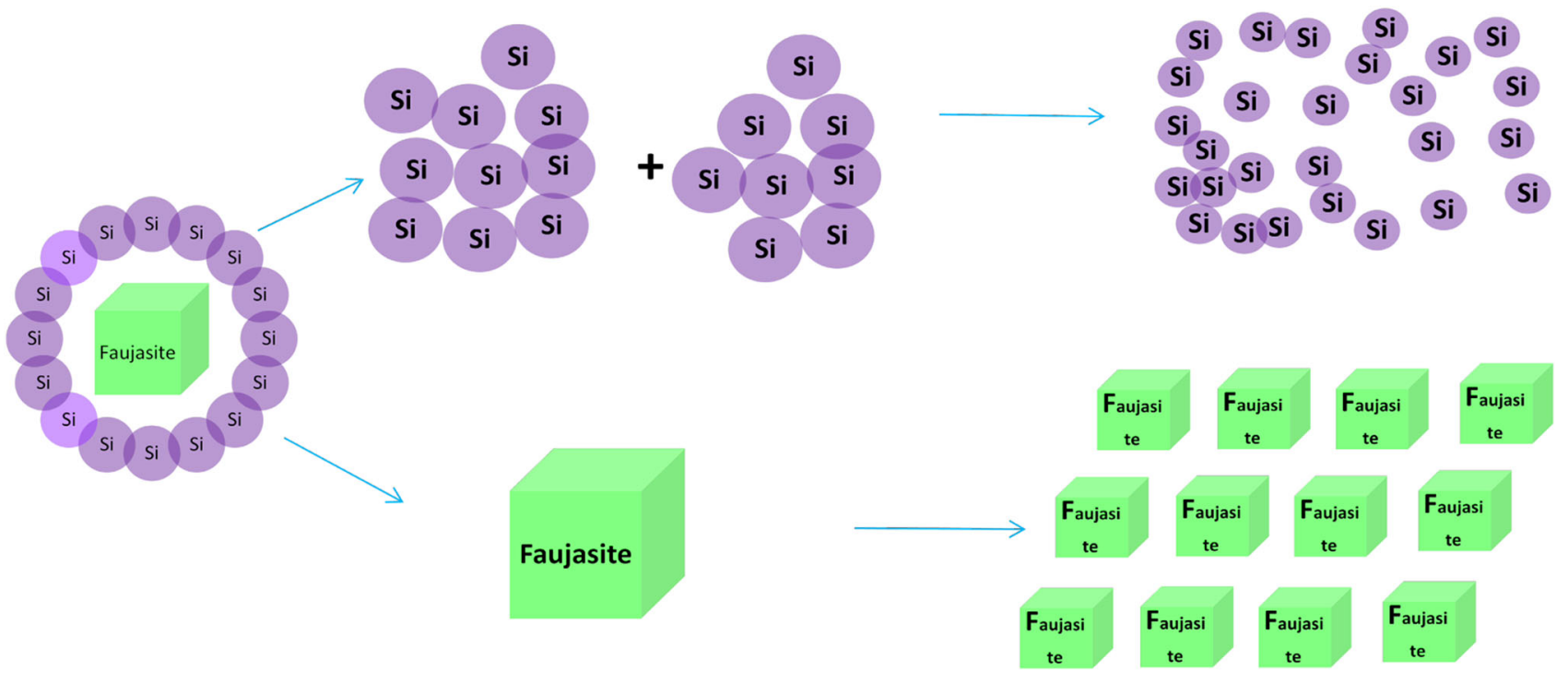

Fig. 2 Schematic diagram of separation between Y zeolite and silica sol (gel)

efficiently improved; the decrease on zeolites' particle size makes the zeolites better-dispersed in FCC catalyst. Therefore, the matrix pre-cracked big heavy oil molecules are much easier to react on the zeolites' active center. This shortens the reaction route of heavy oil molecules. At the same time, due to the decrease of zeolites' particle size, the inner pores of zeolites are shortened; therefore, the reactant, reaction products, and coke precursor are easier to spread and lead to decrease on coke generation and acceleration on heavy oil conversion. Figures 1 and 2 are the particle size comparison on high dispersion $\mathrm{Y}$ zeolite and conventional $\mathrm{Y}$ zeolite.

From Fig. 1, we can see that the high dispersion $Y$ zeolite has a smaller particle size and is relatively well distributed. There are clear boundaries between each crystalline grain without adhesion. Nano-scale Y zeolite' size is smaller than conventional one. On the other hand, the conventional Y zeolites' particle is imbalanced distributed due to adhesion. From Table 3, we can see, compared with the conventional Y zeolite, the novel zeolite's median particle size $D(0.5)$ has decreased by $0.422 \mu \mathrm{m}$ and $D(0.9)$ has decreased by $6.029 \mu \mathrm{m}$.

\section{Thermal and hydrothermal stability}

Table 4 shows the comparison results between hydrothermal and thermal stability of novel and conventional $\mathrm{Y}$ zeolite.

From Table 4, we can see that compared to conventional $\mathrm{Y}$ zeolite, the novel $\mathrm{Y}$ zeolite maintained good relative crystallinity after $2 \mathrm{~h}$ hydrothermal deactivation and the collapse temperature increased $13{ }^{\circ} \mathrm{C}$. This indicates that

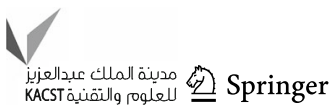


Table 3 Particle size distribution of novel and conventional Y zeolite

\begin{tabular}{lllc}
\hline Items & $D(0.1)(\mu \mathrm{m})$ & $D(0.5)(\mu \mathrm{m})$ & $D(0.9)(\mu \mathrm{m})$ \\
\hline Novel Y zeolite & 0.713 & 2.523 & 8.934 \\
Conventional Y zeolite & 0.756 & 2.945 & 14.963 \\
\hline
\end{tabular}

Table 4 Hydrothermal and thermal stability of novel and conventional Y zeolite

\begin{tabular}{lllll}
\hline Items & $C /$ & $\begin{array}{l}C / C_{0} \text { after } \\
\text { hydrothermal for } 2 \mathrm{~h}\end{array}$ & $\begin{array}{l}A_{0}, \AA \\
C_{0}^{\mathrm{a}}\end{array}$ & $\begin{array}{l}\text { Collapse } \\
\text { temperature }\left({ }^{\circ} \mathrm{C}\right)\end{array}$ \\
\hline $\begin{array}{c}\text { Novel Y } \\
\text { zeolite }\end{array}$ & 56 & 28 & 24.35 & 1019 \\
$\begin{array}{c}\text { Conventional } \\
\text { Y zeolite }\end{array}$ & 47 & 21 & 24.34 & 1006 \\
\hline
\end{tabular}

${ }^{a} \mathrm{C} / C_{0}$ is the relative crystallinity, which is based on the peak height between 23 and $24.5 \mathrm{e}$

Table 5 Acidity of novel and conventional Y zeolite

\begin{tabular}{lll}
\hline Items & \multicolumn{1}{|}{ Acidity $\left(350^{\circ} \mathrm{C}\right)$} & \\
\cline { 2 - 3 } & $\begin{array}{l}\text { Brønsted acid } \\
\text { (umol/g) }\end{array}$ & $\begin{array}{l}\text { Lewis acid } \\
\text { (umol/g) }\end{array}$ \\
\hline Novel Y zeolite & 54.736 & 49.452 \\
Conventional Y zeolite & 26.084 & 71.401 \\
\hline
\end{tabular}

the novel Y zeolite has good hydrothermal stability and thermal stability.

\section{Acidity}

Table 5 shows the comparison results between novel $\mathrm{Y}$ zeolite and conventional zeolite on acidity.

Table 5 shows that, compared with the conventional $\mathrm{Y}$ zeolite, the novel Y zeolite shows excellent selectivity on Brønsted acid.

\section{Catalytic performance}

Table 6 is the evaluation results on CAT-1 and CAT-2 which were tested on fixed fluidization bed FCC unit.

Table 6 shows the fixed fluidization bed FCC unit evaluation result on CAT-1 and CAT-2. From Table 6, it is clear that compared with CAT-1, CAT-2 which containing the novel Y zeolite could increase gasoline yield by $2.39 \%$ points; decrease the heavy oil yield by $1.87 \%$ points; and increase the conversion rate, LCO and total liquid yield by $2.53,1.72$, and $1.63 \%$ points, respectively. Therefore, the novel Y zeolite has features of strong heavy oil conversion ability and increasing total liquid yield.
Table 6 Catalytic cracking results of CAT-1 and CAT-2

\begin{tabular}{lccc}
\hline Product distribution $(\omega \%)$ & CAT-1 & CAT-2 & \multicolumn{1}{c}{$\Delta$} \\
\hline Dry gas & 2.39 & 2.44 & 0.05 \\
LPG & 20.16 & 20.06 & -0.1 \\
Gasoline & 47.06 & 49.45 & 2.39 \\
Diesel & 14.68 & 14.01 & -0.67 \\
Heavy oil & 10.33 & 8.46 & -1.87 \\
Coke & 5.38 & 5.57 & 0.19 \\
Conversion $(\omega \%)$ & 74.99 & 77.52 & 2.53 \\
Light oil $(\omega \%)$ & 61.74 & 63.46 & 1.72 \\
Liquid oil yield $(\omega \%)$ & 81.90 & 83.53 & 1.63 \\
\hline
\end{tabular}

\section{Preparation mechanism}

Figure 2 is the mechanism graph of separation of $\mathrm{NaY}$ zeolite and Si gel. At the end of silicon-alumina zeolites' thermal crystallinity, the zeolite needs to be separated from crystallinity mother liquid. In industrial application, vacuum filtration is adopted to separate zeolite crystal and inorganic salt-rich crystallinity mother solution. During the separation, large amount of residue of inorganic salt ions is left on the filter cake. In industrial situation, distilled water is often used to wash off these inorganic salt ions. When filtering and separating zeolite crystallinity system, there are large quantity of unreacted silicates in the residue inorganic salt ions left on the filter cake. Silicate ion is a kind of special ion which is very sensitive to $\mathrm{pH}$ value. Under normal circumstances, the higher $\mathrm{pH}$ value a system has, the more stable silicate is; but when the system's pH value decreases, silicates would be very active to form gel. When wash the zeolite's filter cake, the system $\mathrm{pH}$ value is low; therefore, silicates are active and would form a large quantity of amorphous gel. This gel not only blocks filter cloth and cause bad effect on filtration speed, but also significantly influence zeolites' physical and chemical properties, such as degree of crystallinity, dispersion, and stability. Therefore, after pretreatment on $\mathrm{NaY}$ zeolite with alkaline solution and then separation with mother solution, $\mathrm{NaY}$ zeolite and Si gel can be effectively separated.

\section{Conclusions}

(1) There is a large amount of gel in Y zeolite's crystallinity seriflux; pretreatment on $\mathrm{NaY}$ zeolite with alkaline solution can effectively separate Y zeolite from Si gel.

(2) The high dispersion Y zeolite has a smaller particle size and is relatively well distributed. There are clear boundaries between each crystalline grain without adhesion. On the other hand, the conventional Y zeolite's nanoparticles are imbalanced distributed with adhesion. 
Compared to the conventional Y zeolite, the novel zeolite's median particle size $D(0.5)$ has decreased by $0.422 \mu \mathrm{m}$ and $D(0.9)$ has decreased by $6.029 \mu \mathrm{m}$.

(3) The novel Y zeolite maintained good relative crystallinity after $2 \mathrm{~h}$ hydrothermal deactivation and the collapse temperature increased $13{ }^{\circ} \mathrm{C}$. This indicates that the novel Y zeolite has good hydrothermal stability and thermal stability.

(4) The novel zeolite shows excellent selectivity on Brønsted acid.

(5) On the basis of maintaining coke and dry gas yields, CAT-2 which containing the novel Y zeolite could increase gasoline yield by $2.39 \%$ points; decrease the heavy oil yield by $1.87 \%$ points; and increase the conversion rate, LCO and total liquid yield by 2.53, 1.72, and $1.63 \%$ points, respectively. Therefore, the novel $\mathrm{Y}$ zeolite has the features of strong heavy oil conversion ability and increasing total liquid yield.

Acknowledgments The authors thank the Ministry of Science and Technology Management of PetroChina and National Natural Science Foundation of China (No.21476263) for providing financial support.

Open Access This article is distributed under the terms of the Creative Commons Attribution 4.0 International License (http:// creativecommons.org/licenses/by/4.0/), which permits unrestricted use, distribution, and reproduction in any medium, provided you give appropriate credit to the original author(s) and the source, provide a link to the Creative Commons license, and indicate if changes were made.

\section{References}

1. Cerqueira HS, Caeirob G, Costac L, Ribeiro FR (2008) Deactivation of FCC catalysts. J Mol Catal A Chem 292:1-13

2. Thomas B, Bibhuti BD, Sugunan S (2006) Rare earth exchanged $\left(\mathrm{Ce}^{3+}, \mathrm{La}^{3+}\right.$ and $\left.\mathrm{RE}^{3+}\right) \mathrm{H}-\mathrm{Y}$ zeolites as solid acid catalysts for the synthesis of linear alkyl benzenes. Microporous Mesoporous Mater 95:329-338

3. Fan J, Liu Z, Wang Z, Liao Y, Gao X (2013) Performance comparison and modification research on ZSM-5 molecular sieves for improving output of low-carbon olefins. Ind Catal 21:41-45

4. Sun Dongliang, Zhao Yong (2005) Influence of alkali condition on removing $\mathrm{Na}$ of $\mathrm{NaY}$ molecular sieve and its structure. Petrochem Technol Appl 23:346-349

5. Ai-qun Z, Ai-zhen T, Lanhua L, Jiangtao F, Yu X, Zhifeng W (2009) Structure and operation of a novel three-channel fixed fluidized bed testing equipment XGL-2 $\times 3$ for catalytic cracking. Petrochem Technol Appl 27:78-82 